
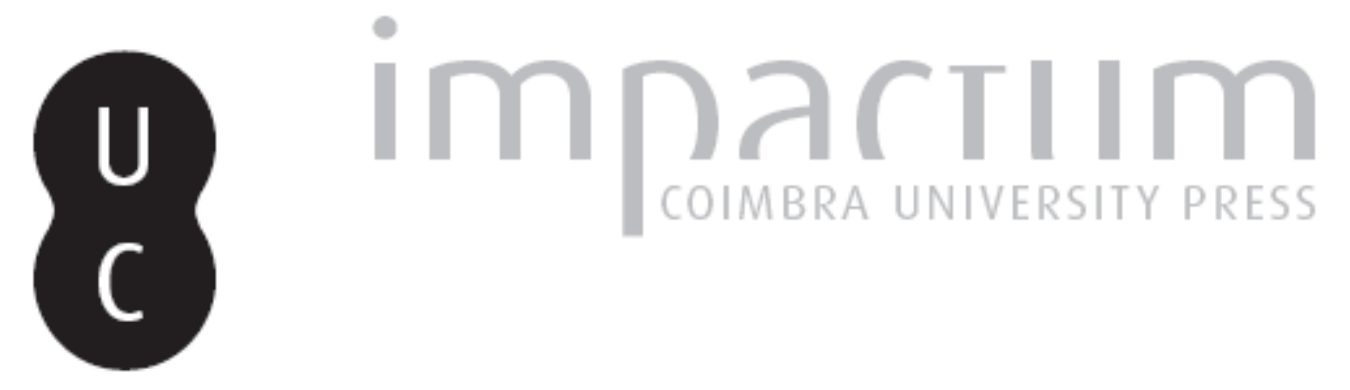

\title{
[Recensão a] ROSA (João Mendes) e BIZARRO (Joana), A Urbs Romana da Encosta Meridional da Gardunha
}

Autor(es): $\quad$ Encarnação, José d'

Publicado por: Faculdade de Letras da Universidade de Coimbra

URL persistente:

URI:http://hdl.handle.net/10316.2/38802

DOI:

DOI:http://dx.doi.org/10.14195/1647-8657_53_8

Accessed : $\quad$ 26-Apr-2023 14:00:22

A navegação consulta e descarregamento dos títulos inseridos nas Bibliotecas Digitais UC Digitalis, UC Pombalina e UC Impactum, pressupõem a aceitação plena e sem reservas dos Termos e Condições de Uso destas Bibliotecas Digitais, disponíveis em https://digitalis.uc.pt/pt-pt/termos.

Conforme exposto nos referidos Termos e Condições de Uso, o descarregamento de títulos de acesso restrito requer uma licença válida de autorização devendo o utilizador aceder ao(s) documento(s) a partir de um endereço de IP da instituição detentora da supramencionada licença.

Ao utilizador é apenas permitido o descarregamento para uso pessoal, pelo que o emprego do(s) título(s) descarregado(s) para outro fim, designadamente comercial, carece de autorização do respetivo autor ou editor da obra.

Na medida em que todas as obras da UC Digitalis se encontram protegidas pelo Código do Direito de Autor e Direitos Conexos e demais legislação aplicável, toda a cópia, parcial ou total, deste documento, nos casos em que é legalmente admitida, deverá conter ou fazer-se acompanhar por este aviso.

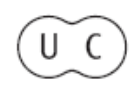


CONIMBRIGA

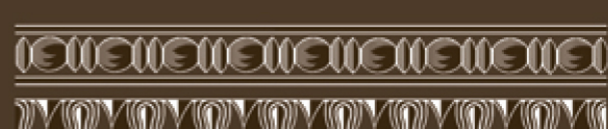

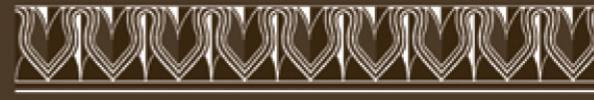

INSTITUTO DE ARQUEOLOGIA

VOLUME LIII • 2014

FACULDADE DE LETRAS 


\section{RECENSÕES BIBLIOGRÁFICAS}

ROSA (João Mendes) e BIZARRO (Joana), A Urbs Romana da Encosta Meridional da Gardunha. Edição de Capitulum, Oeiras, 2014. 72 páginas ilustradas. Concepção gráfica de Rute Campanha. ISBN: 978-989-99015-2-0.

\section{http://dx.doi.org/10.14195/1647-8657_53_8}

No âmbito do II Congresso Internacional de Arqueologia da Região de Castelo Branco, comemorativo dos 100 anos da Sociedade dos Amigos do Museu de Francisco Tavares Proença Júnior, que decorreu no referido museu de Castelo Branco, apresentou Pedro Miguel Salvado, no dia 10 de Abril de 2015, o livro A Urbs Romana da Encosta Meridional da Gardunha, da autoria de João Mendes Rosa e de Joana Bizarro, edição que teve o patrocínio das autarquias envolvidas: a Câmara Municipal do Fundão e as freguesias de Alpedrinha, Atalaia do Campo, Castelo Novo e Póvoa da Atalaia.

Conta a obra com prefácio do Doutor Jorge de Alarcão, que desde há muito vem investigando o que teria sido o panorama organizativo, nomeadamente em termos de povoamento no tempo dos Romanos, do que é hoje a «Beira Interior». Haja em vista o seu recente livro A Beira Baixa. Terra tomada sem guerra (Coimbra, 2013), onde largamente coteja abundante e mui variada documentação com vista a descobrir antigas designações dos aglomerados populacionais hodiernos, e o artigo «O templo romano de Orjais (Covilhã) e a sua bacia de visão» (Conimbriga 522013 67-128), assinado de parceria com Pedro C. Carvalho, José Luís Madeira e Marcos Osório, em que, como se esclarece logo no resumo, depois de se haver verificado que, desse templo, a vista abarcava um território num arco de $25 \mathrm{~km}$ «para vários lados», os autores se interrogam «sobre se a área de visão corresponderia, ou não, a uma civitas - e esta reflexão condu-los a uma discussão sobre o controverso problema da localização dos municipia mencionados na inscrição da ponte de Alcântara, CIL II 760», um tema que o Professor amiúde vem abordando (vejam-se, a título de exemplo: «Os Montes Hermínios e os Lusitanos», in Livro de homenagem a Orlando Ribeiro, $2 .^{\circ}$ vol., Lisboa, 1986, p. 41-48; «Sobre a localização dos Lancienses e Tapori», in M. Justino Maciel (ed.), Miscellanea em homenagem ao Professor Bairrão Oleiro, Lisboa, 1996, p. 39-44 [de colab. com Flávio Imperial]; «On the ciuitates mentioned in the inscription on the bridge at Alcântara», Journal of Iberian

Conimbriga, 53 (2014) 225-233 
Archaeology, 0, 1998, p. 143-157). E não apenas em relação à zona da ora chamada Beira Interior.

A preocupação em atribuir uma 'categoria' aos vestígios romanos dispersos pelo território derivou não apenas da elaboração do seu Roman Portugal (WARMINSTER, 1988) - que postulara alguma sistematização e trouxera, por outro lado, uma perspectiva mais ampla do que eram, na altura, os conhecimentos que se tinham acerca do «Portugal romano» (passe o anacronismo da designação) - mas também, de modo especial, com as específicas orientações didácticas pós-25 de Abril, que, aliás, acabaram por 'determinar' esse projecto de se cartografar com a maior exactidão o resultado de tais conhecimentos.

Explico-me.

Uma das cadeiras constantes da Pré-Especialização em Arqueologia, que entrou em vigor, em 1975-1976, na Faculdade de Letras da Universidade de Coimbra era Técnicas da Investigação Arqueológica. E, como trabalho para a avaliação final, era solicitado aos estudantes que lançassem as bases de «cartas arqueológicas» de freguesias ou concelhos, a partir, por exemplo, de minuciosa consulta dos microtopónimos constantes nos registos cadastrais prediais das repartições de Finanças. Assim, a par de mui cuidadosa prospecção no terreno, feita antes ou depois de exaustiva recolha dos microtopónimos indiciadores de vestígios antigos, era possível, confrontados também com eventuais dados da tradição oral, determinar sítios susceptíveis de deterem interesse histórico-arqueológico, a preservar. Complexa sempre fora a classificação de locais que remontavam à Pré-História; mas, no caso da época romana, mais «perto» de nós, a tentação era... eloquentemente sedutora! Restos arquitectónicos imponentes indiciariam um aglomerado urbano, uma urbs. Mas... urbs seria cidade? E civitas o que era? E, se a presença de mosaicos poderia ser sinal (quase seguro, pensava-se...) de estarmos perante uma villa, o certo é que também se haviam detectado já estruturas construtivas que, não fazendo suspeitar da existência de um aglomerado urbano, também não obedeciam propriamente aos esquemas habituais de uma villa...

Um estudo mais atento das inscrições romanas - sobretudo as funerárias e as votivas, as mais frequentes em âmbito rural - veio, aparentemente, ajudar na questão, porque se identificaram vicani a prestar culto a Júpiter. Eram, portanto, os habitantes de um vicus, cuja designação vinha na epígrafe. Entre si, os vicani poder-se-iam chamar de vicini, «vizinhos», designação que, mesmo na actualidade, mais se adequa - apesar de todas as mui saudáveis tentativas de a alargar a âmbitos urbanos - a uma aldeia ou lugar.

Há, porém, mesmo na actualidade, dois níveis identificativos: o real e o administrativo. Temos lugares e aldeias que querem, algumas, ser vilas; e vilas que querem, algumas, ser cidades; mas, a nível administrativo, ser vila não implica ser município e ser cidade não é habitualmente sinónimo de 'capital de distrito'. Esta reflexão, à primeira vista simplória, questão de lanacaprina, será, porventura, oportuna, se a quisermos aplicar à época romana: a que corresponde a civitas Cobelcorum, que, em Almofala (Figueira de Castelo 
Rodrigo), presta culto a Júpiter Óptimo Máximo (AE 1998, 700) num enquadramento arqueológico invulgar? Assumirá a capitalidade em relação aos aglomerados populacionais porventura seus vizinhos, uma vez que, inclusive, há testemunhos de quem faça questão em ser identificado Cobelcus? Em Marialva (Meda), o filho de um Flaccus assume-se como Cobelcus, quando homenageia uma divindade cujo nome se desconhece (AE 1985, 526); é igualmente o caso de um Modestus, Ambati filius, em cujo epitáfio, achado em Escalhão, Figueira de Castelo Rodrigo (CIL II 433), se assinala a sua condição de Cobelcus; ou, ainda, a de Martialis Oclati f(ilius), cuja lápida funerária se encontrou em Mérida e se diz Cobelcus também (HEp 4, 1994, 174).

Já, por seu turno, uma civitas Aravorum, que oficialmente homenageia o imperador Adriano (veja-se: Encarnação, José d', «Homenagem da civitas Aravorum ao imperador Adriano», Praça Velha, 34, 2014, p. 127-151 - http:// hdl.handle.net/10316/23558) terá, sem dúvida, estatuto elevado, até porque assumem alguma relevância os vestígios arqueológicos postos a descoberto no local donde a epígrafe proveio: «São aliás notáveis os vestígios de um centro urbano não menos importante que o de Idanha-a-Velha», escreve-se no artigo citado mais adiante (Conimbriga 522013 102). Aliás, talvez estes dois exemplos não deixem de ser significativos: homenagem ao imperador - importância relevante, mormente do ponto de vista administrativo; ex-voto a uma divindade, mesmo que Júpiter, poderá ser apenas sinónimo de uma identidade local, das suas gentes, e não obrigatoriamente algo mais.

No caso vertente, a questão que Mendes Rosa e Joana Bizarro procuram solucionar é a da identificação da cidade de Petratinia, sita «na encosta da serra da Gardunha» e que poderia ser, na verdade, uma invenção criada «nos séculos XVII e XVIII» «assente em achados na Quinta do Ervedal ou em área vizinha» (p. 6).

$\mathrm{Na}$ verdade, a primeira dúvida é logo propositadamente suscitada pelo título e, designadamente, pela apresentação da palavra «urbs» entre aspas. E, para a resolver, hão-de confrontar-se os dados arqueológicos recolhidos no decorrer das escavações levadas a efeito na Quinta do Ervedal (Alpedrinha, Fundão) com o facto de fontes antigas situarem algures na encosta sul da Serra da Gardunha a cidade romana de Petrata ou Petratinia, inclusive referindo, como prova, achados arqueológicos de monta.

A análise das 'fontes escritas' constitui, pois, o $1^{\circ}$ capítulo da obra, que muito deve, nesse aspecto, à aturada investigação levada a cabo sobre a história do Fundão por Joaquim Candeias da Silva. Seguem-se-lhe: a enumeração das «estações romanas da encosta sul da Gardunha»; o ênfase que há a dar a estarmos localmente perante uma 'encruzilhada hídrica', factor que sempre favorece a fixação das gentes, assim como a circunstância de poder garantir-se a existência aí de um complexo sistema viário romano.

Após análise dos elementos susceptíveis de contribuir para a localização da vetusta cidade apregoada pelas fontes, os autores apontam Ervedal como sendo «um assentamento estratégico privilegiado» (p. 36-44), demorando-se, 
de seguida, na minuciosa descrição dos resultados obtidos nas campanhas arqueológicas levadas a cabo, sob sua orientação, na «estação romana do Ervedal» (p. 45-60), onde, inclusive, detectaram dois complexos termais, um dos quais público e, numa das áreas escavadas, «cinco fases de ocupação»: um primeiro edifício monumental foi adaptado a domus com balneum, readaptado numa fase subsequente, que deu lugar, de seguida, a um espaço «para actividades domésticas»; a $5^{\text {a }}$ fase corresponde a «uma ocupação tardia como espaço funerário» (p. 50). Vem este capítulo ilustrado com fotografias e desenhos das estruturas e dos objectos mais significativos, entre os quais se conta o fragmento de bronze de uma dobradiça com singular decoração geométrica.

Uma nota final dá conta da opinião dos autores acerca da origem etimológica do topónimo Alpreada, que relacionam com o topónimo actual «Terra das Pedras» e que, atendendo até ao facto de, por ali, haver muito o hábito de se edificarem as casas sobre as rochas, Alpeadra derivará de Petra, não tendo a ver - como já chegou a ser sugerido - com a preexistência de uma via romana. Jorge de Alarcão (2013, 40-41), partindo do facto de o verbo 'prear' ter o sentido de "capturar» e de, por isso, "preada' poder significar "presa", "barragem" (o al- inicial de Alpreada seria o normal artigo árabe), a alusão a uma barragem romana próxima, mantém «a hipótese de o nome de Alpreada derivar de Preada e de este ser o que se dava à referida barragem romana».

Assume-se, por conseguinte, o livrinho como assaz oportuna reflexão monográfica, com vista a justificada classificação, como vicus romano, do sítio arqueológico da referida Quinta do Ervedal, porventura designado Talabara, uma vez que até se documenta, em Alpedrinha, um Talabarius (AE 1967, 141), quiçá seu natural, a dedicar um altar a Marte. Aliás, se é correcta a interpretação da bem conhecida epígrafe de Capinha (cf. CARVALHO, Rogério, e ENCARNAÇÃo, José d', «Inscrição rupestre romana procedente de Capinha», Trebaruna 31994 43-53), em que se perpetua a memória de um natural de v( $i$ co) Talabara, essa hipótese ganha consistência. No citado texto de Conimbriga 52, os autores - que naturalmente desconheciam esta monografia - escrevem: «Haveria, pois, um aglomerado urbano secundário chamado Talabara, eventualmente sobre o rio ou ribeiro *Talabarium, ao qual afluiria o ribeiro *Talabariolum - hoje, ribeira de Taveiró» (p. 92).

E se haverá, por consequência, elementos a pôr em paralelo, à medida que eles forem sendo conhecidos, dir-se-á que Mendes Rosa e Joana Bizarro aqui exaustivamente convocaram, para efeito da demonstração em vista, toda a documentação disponível. Nesse aspecto, portanto, um testemunho exemplar.

Uma segunda edição deverá ser alvo, porém, de aturada revisão do ponto de vista tipográfico, pois abundam as gralhas. Há, amiúde, pontuação incorrecta e falhas de concordância. Que significa, por exemplo, a frase «Candeias da Silva, que rejeita desde 1993 a existência de Petrata, apenas admite a mesma se ela for considerada fora dos auspícios de Alpedrinha» (p. 29)? Faltam palavras, aqui e além: «[...] uma anta entre Atalaia e Alpedrinha, destruída 1901 e quatro machados [...]» (p. 19). Anote-se, em relação à p. 27, que o 
antropónimo latino é Caeno (no nominativo), pelo que se deveria ter escrito «filho de Caeno»; aliás, a epígrafe em referência (fig. 6) não será exactamente «a inscrição funerária de Cláudio Severo», pois que o seu nome é aí mencionado não como defunto mas sim como dedicante: os defuntos são os seus pais. $\mathrm{Na}$ p. 54, diz-se que se realizou «uma micro-sondagem no C8 (balneum I)» e, na página seguinte, a legenda das imagens traz «armela de sítula (C8)»; C8 é, naturalmente, uma identificação arqueológica, mas a inserção desse dado assim, sem haver, que eu recorde, identificação doutras quadrículas ou estratos, pode induzir em erro ou trazer perplexidade. Não obedece a uma regra clara o uso dos itálicos, habitual para os vocábulos latinos ou para identificar o título de uma obra. Na bibliografia: nem sempre é seguida a ordem alfabética por apelido dos autores; incluem-se obras que não estão citadas no texto; não se faz a distinção entre artigos e livros; há inexactidões... Exemplifico (p. 68): «FARIA, A Marques de (1989) - «A presença romana no território português» in Conimbriga, p. 66» poder-se-ia ter apresentado assim: FARIA, A. Marques de (1989) - «Sobre a presença romana no actual território português. Apostilas ao recente livro do Prof. Jorge de Alarcão» in Conimbriga, XXVIII, p. 53-69. Também a referência "SARMENTO, Martins (1881) - «Expedição científica à Serra da Estrela» - Secção de Arqueologia" deverá vir a ser substituída por SARMENTO, Martins (1883) - Expedição scientifica à Serra da Estrella em 1881 - Secção de Arqueologia, Lisboa, Imprensa Nacional, pois se trata de um opúsculo de 26 páginas e 10 estampas, com o título que pus em itálico.

Num texto, como o presente, de bom recorte científico, importará evitar tudo quanto possa beliscar o valor que efectivamente detém.

José d'Encarnação

Faculdade de Letras / Universidade de Coimbra

Conimbriga, 53 (2014) 225-233 